\title{
Research Paper: The Relationship Between Areas of Occupation and Severity of Depression, Anxiety, and Stress in Parkinson's Disease
}

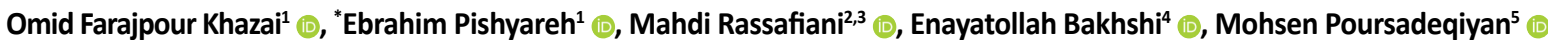

1. Department of Occupational Therapy, University of Social Welfare and Rehabilitation Sciences, Tehran, Iran.

2. Department of Occupational Therapy, Faculty of Allied Health Sciences, Kuwait University, Kuwait, Kuwait.

3. Pediatric Neurorehabilitation Research Center, University of Social Welfare and Rehabilitation Sciences, Tehran, Iran.

4. Department of Biostatistics, University of Social Welfare and Rehabilitation Sciences, Tehran, Iran.

5. Health Sciences Research Center, Torbat Heydariyeh University of Medical Sciences, Torbat Heydariyeh, Iran.

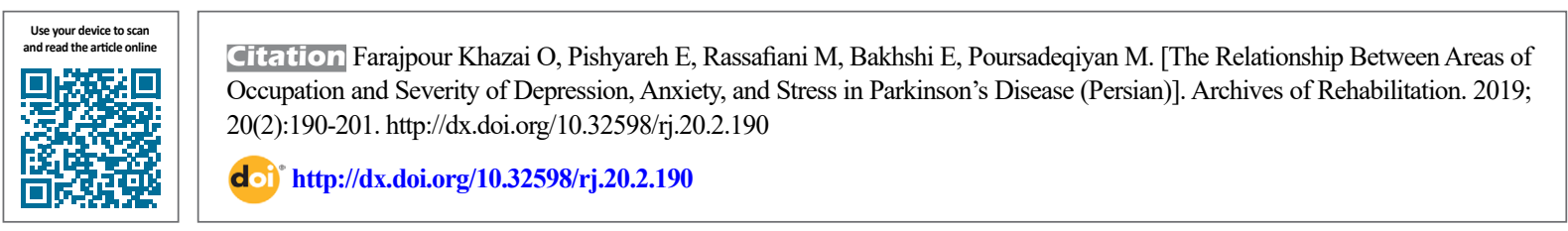

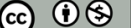

Received: 22 Dec 2018

Accepted: 11 Apr 2019 Available Online: $01 \mathrm{Jul} 2019$

Keywords:

Anxiety, Depression, Occupational performance, Parkinson's disease, Stress

\section{ABSTRACT}

Objective Parkinson's Disease (PD) is a neurodegenerative progressive condition with a number of nonmotor symptoms such as depression, anxiety, and stress. These have the most debilitating characteristics and increase the severity and progression of the disease and often reduce functional ability in the sufferers. For this reason, they may, over time, lose their daily living activities skills (basic and instrumental) and social participation. The current study investigated the relationship between the areas of occupation and severity of depression, anxiety, and stress in PD.

Materials \& Methods In this cross-sectional (descriptive-analytical) study, 91 PD patients referring to rehabilitation centers and hospitals in Tehran City, Iran, were selected through convenience sampling method. After obtaining approval from the University of Social Welfare and Rehabilitation, we referred to the centers and hospitals; if managers of the centers accepted to cooperate with the research team, the study was conducted in accordance with the inclusion criteria in that center. The Assessment of Life Habits (Life-H) test was used to evaluate the areas of occupation and the Depression, Anxiety and Stress Scale (DASS-21) was applied to assess depression, anxiety, and stress. Life-H test subscales were categorized by the occupational therapists of the university, based on the classification of the areas of occupation. The obtained data were analyzed using Pearson's correlation coefficient, Spearman's rank correlation coefficient, multiple regression analysis, focal correlation, Independent Samples t-test and Mann-Whitney U test in SPSS.

Results The collected results indicated a reverse and significant correlation between the level of Activities of Daily Living (ADL)'s participation and depression. Additionally, the correlation between the levels of participation in education and leisure was inverse and significant in terms of anxiety and stress. The correlation coefficient between the areas of occupation and depression was as $r=0.362, P=0.06$; between the areas of occupation and anxiety was as $r=0.49, P=0.001$; and between the areas of occupation and stress was as $r=0.5$, $\mathrm{P}=0.001$. There was a significant correlation between the different areas of occupation and stress and anxiety; however, the correlation between the areas of occupation and depression was not significant. Focal correlations between the areas of occupation and nonmotor symptoms (depression, anxiety, and stress) were equal to $\mathrm{r}=0.55, \mathrm{P}=0.05$ and significant.

Conclusion There was a significant relationship between the areas of occupation and the incidence of nonmotor symptoms (depression, anxiety, and stress) in people with PD. Therefore, we can facilitate the direction of rehabilitation and occupational therapy's settings for clinicians, by identifying the areas of occupation that are more affected by the disease; this may help to provide disease-related facilities and may have economic benefits for caregivers of PD patients.

\section{* Corresponding Author:}

Ebrahim Pishyareh, PhD.

Address: Department of Occupational Therapy, University of Social Welfare and Rehabilitation, Tehran, Iran.

Tel: +98 (912) 0813693

E-Mail: pishyareh.cog@gmail.com 


\title{
بررسى ارتباط بين حيطدهاى أكوييشن و شدت ميزان افسردتى، اضطراب و استرس در بيماران ياركينسون
}

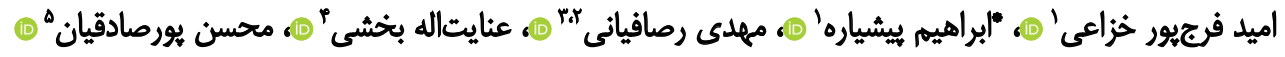

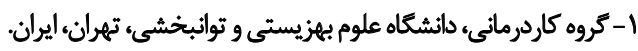

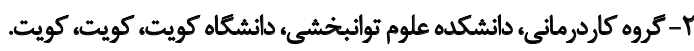

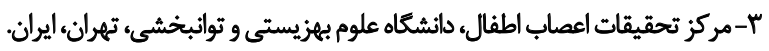

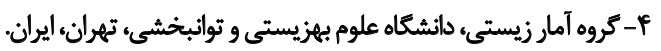

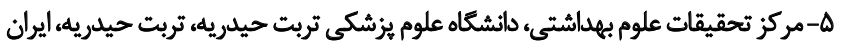

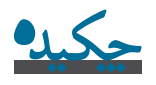

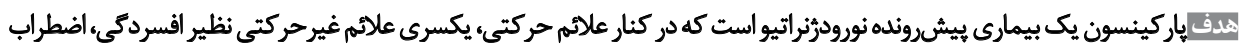

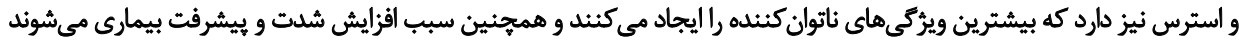

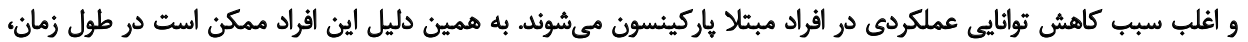

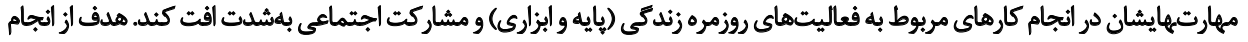

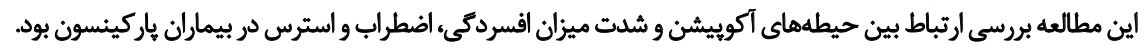

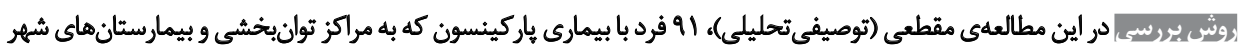

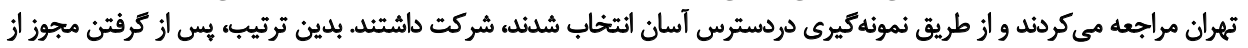

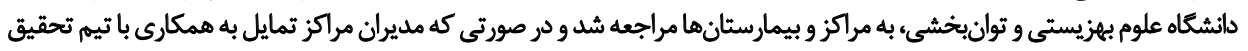

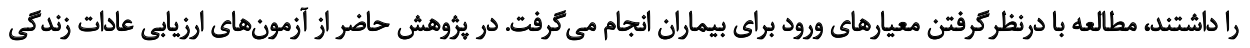

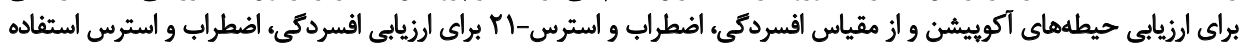

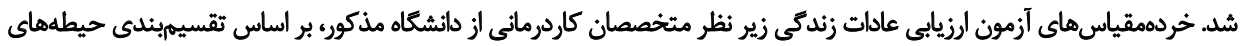

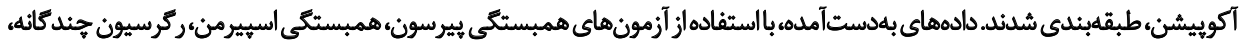

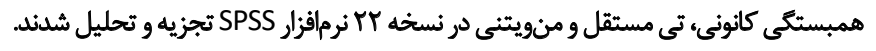

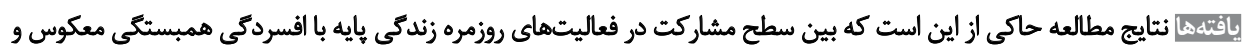

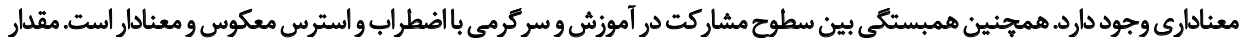

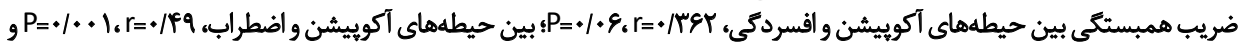

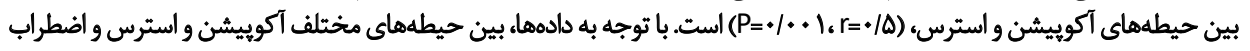

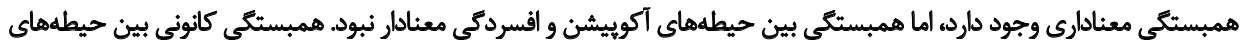

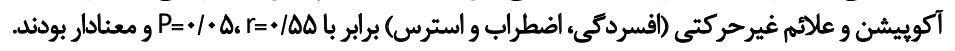

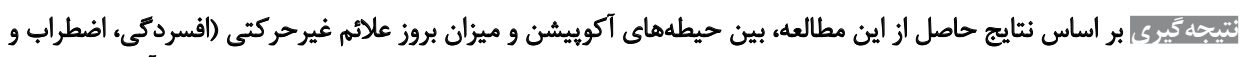

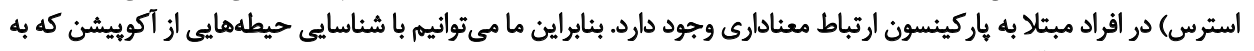

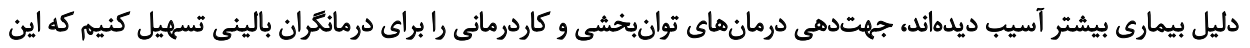

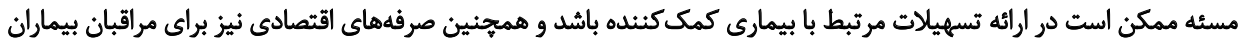
ثياركينسون به همراه داشته باشئه
\end{abstract}

تاريخ دريافت: ا.دى تاريخ يذيرش: بr فروردين

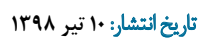




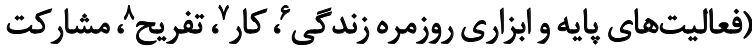

مقدمه

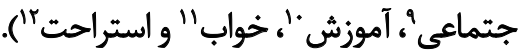

هركدام از اين حيطهها در افراد بسته به اينكه در جه محيطى إنهي

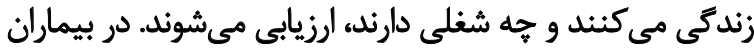

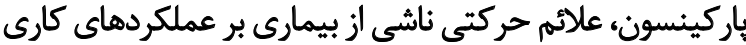

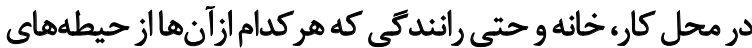

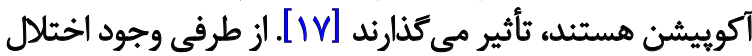

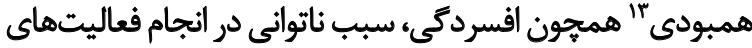

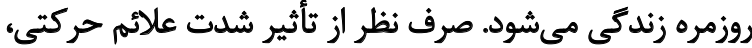

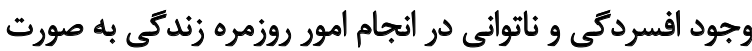

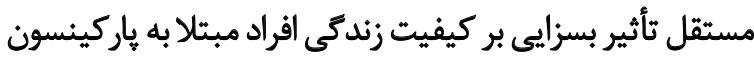

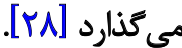

با درنظركرفتن تمامى مشكلات ناشى از بروز و تشديد علائم

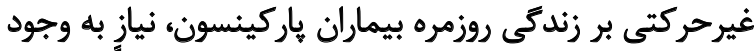

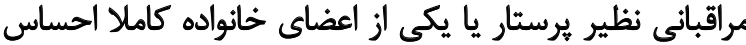

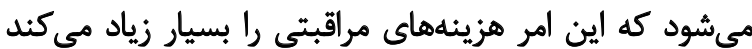

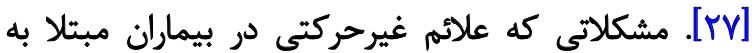

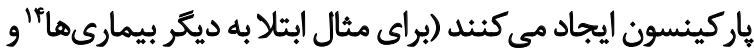

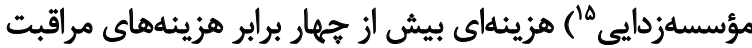

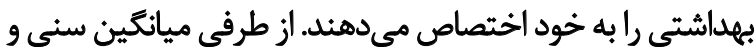

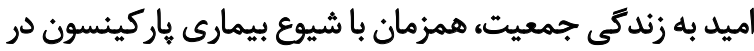

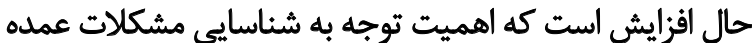

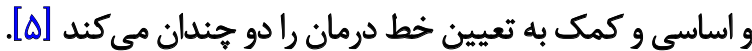

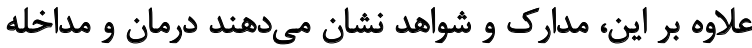
زودهنكام و مستمر افسردگى، تأثيرات مثبتى رئى روى عملكرد

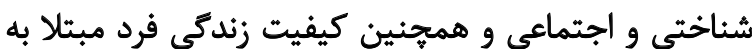

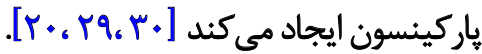

در همين راستا، كاداستيك" و و همكارانش دريافتند علاثم غيرحركتى ارتباط مستقيم و قوى

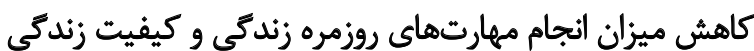

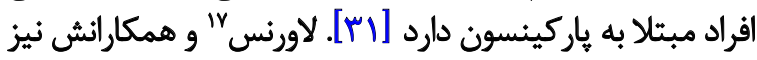

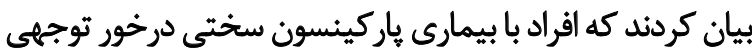

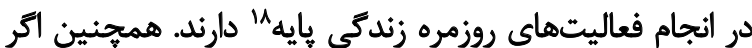

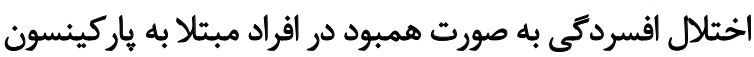

6. Basic and instrumental activity of daily living 7. Work

8. Leisure

9. Social participation

10. Education

11. Sleep

12. Rest

13. Comorbid

14. Morbidity

15. Institutionalization

16. Kadastik-Eerme

17. Lawrence

18. Activities of Daily Living (ADL)

بيمارى :اركينسون بعد از آلزايمر شايعترين بيمارى

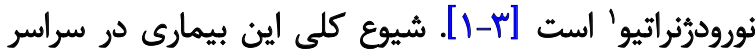

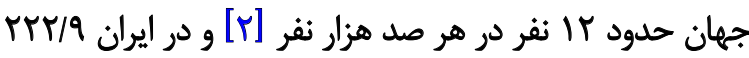

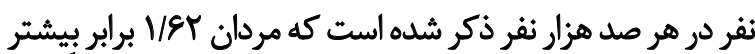

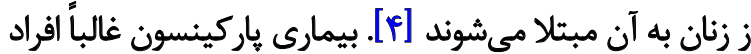

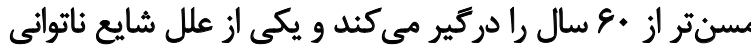

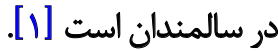

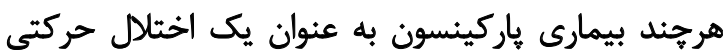

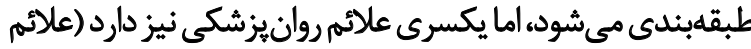

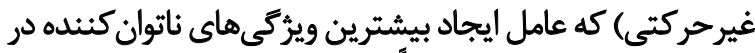

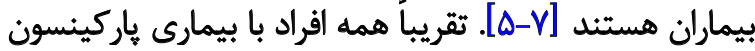

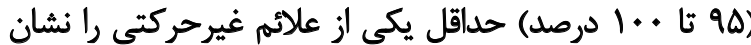

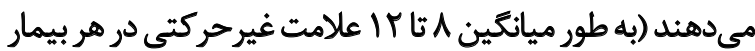

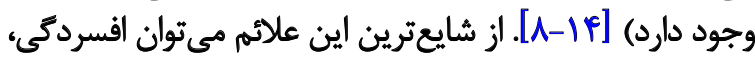

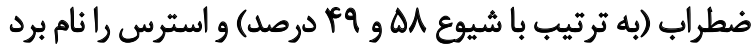

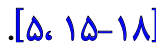

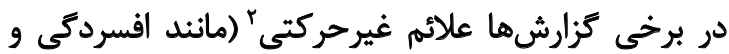

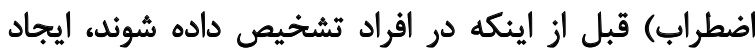

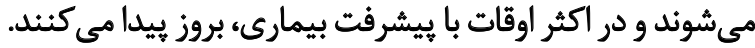

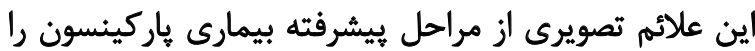

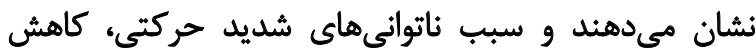

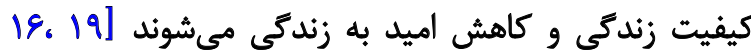

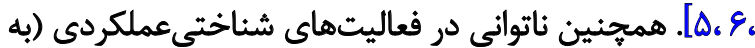

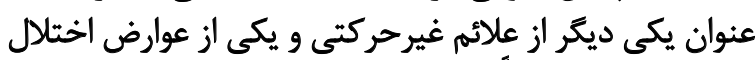

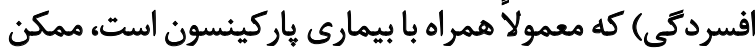

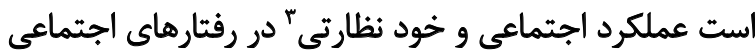

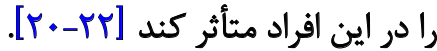

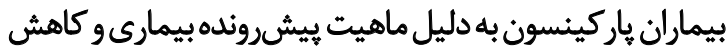

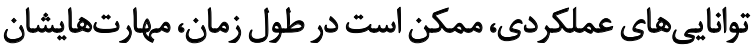

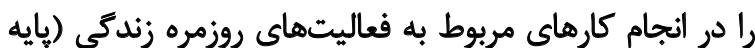

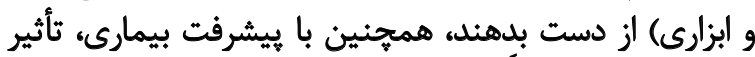

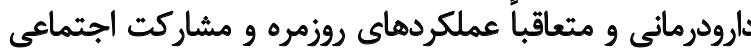

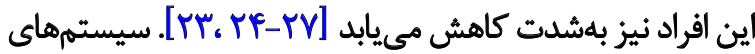

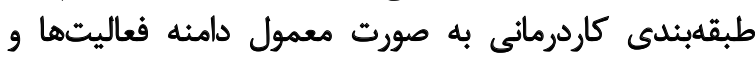

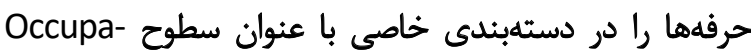
tion

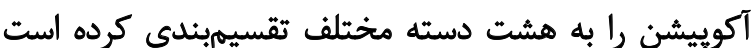

1. Neurodegenerative

2. Non-Motor Symptoms (NMS)

3. Self-monitoring

4. Areas of occupation

5. American Occupational Therapy Association (AOTA) 
نمونه با توان •A درصد و خطاى آزمون ه درصد و با استفاده

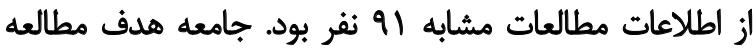

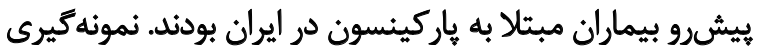

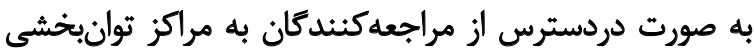

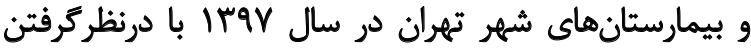
معيارهاى ورود و خروج مطالعه حاضر صورت ترفت دال

معيارهاى ورود به مطالعه شامل تشخيص بيمارى ياركينسون

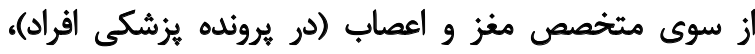

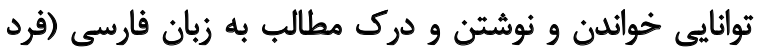

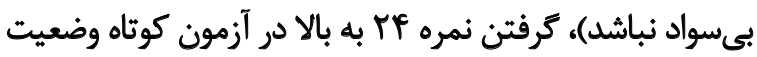

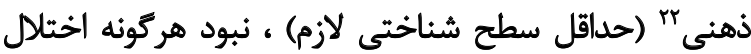

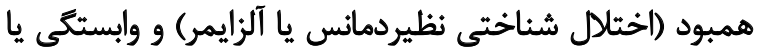

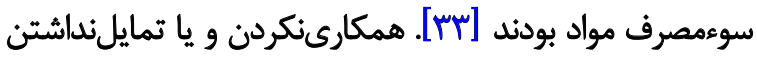

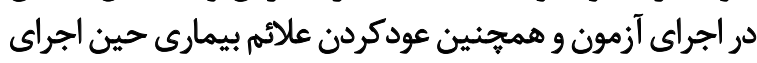
آزمون، جزء معيارهاي خروج أمون بودند.

خردهمقياسهاى جمعيتشناختى يُروهش حاضر شامل سن،

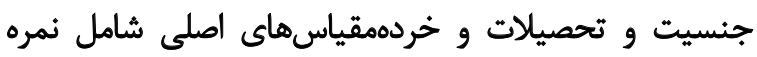

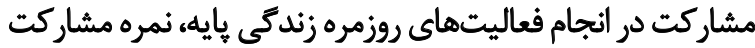

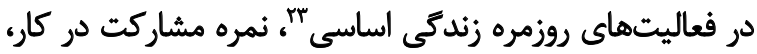

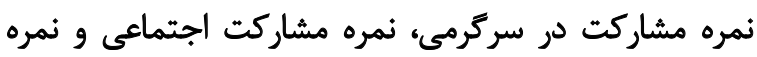

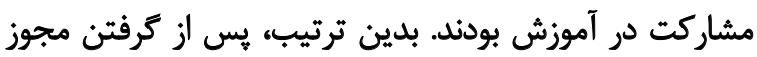

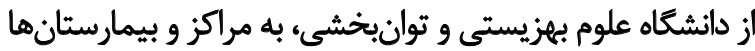

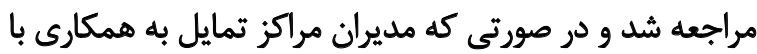

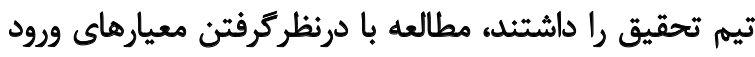

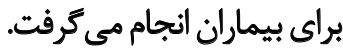

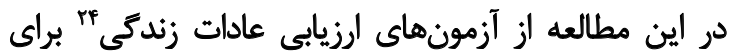

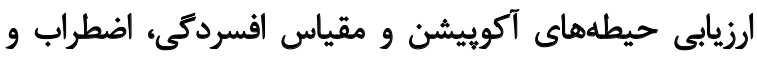

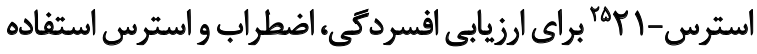

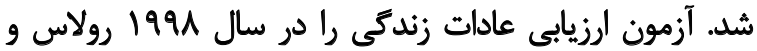

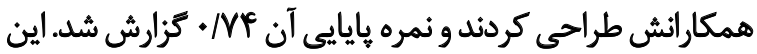

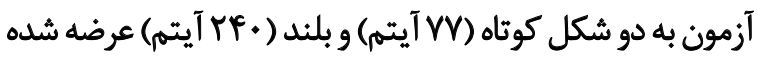

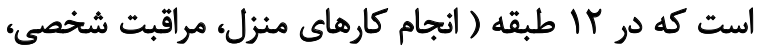

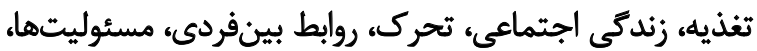

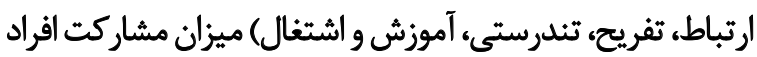

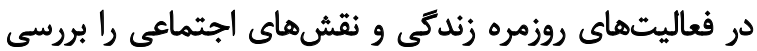

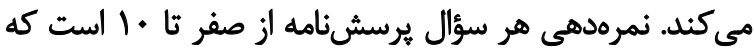

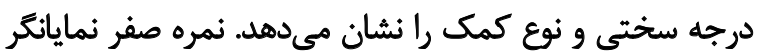

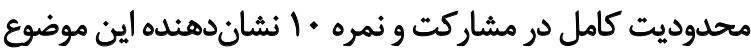

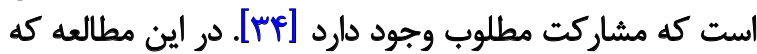

22. Mini-Mental State Examination (MMSE)

23. Activities of Daily Living (IADL)

24. Assessments of Life Habits (Life-H)

25. Depression, Anxiety and Stress Scale-21 (DASS-21)

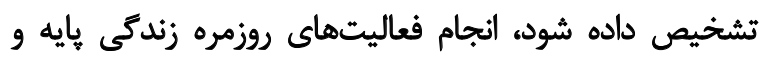
كيفيت زندكى مربوط به سلامت (HRQOL)

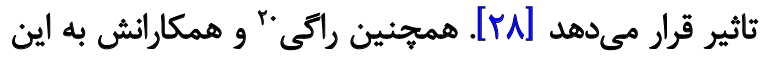

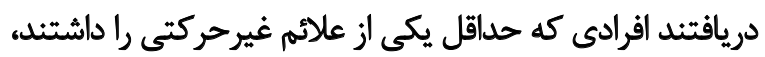

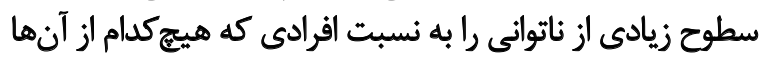

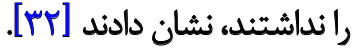

مطالعات مختلف زيادى روى نقاط ضعف و قدرت بيماران

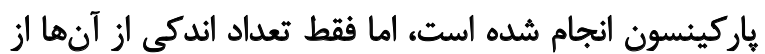

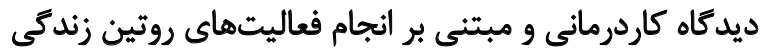

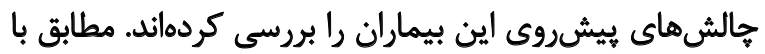

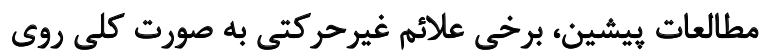

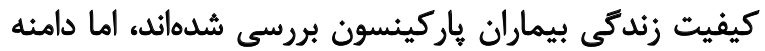

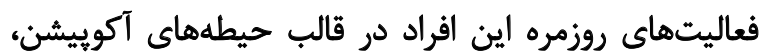

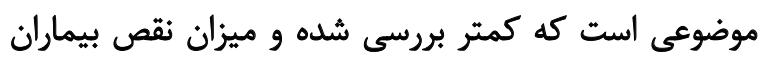

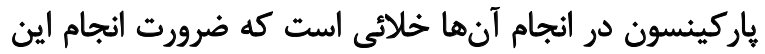

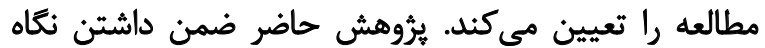

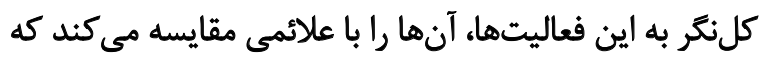

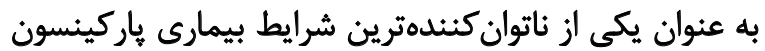

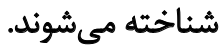
توانايى انجام حيطههاى آكوييشن از جمله مواردى است كه

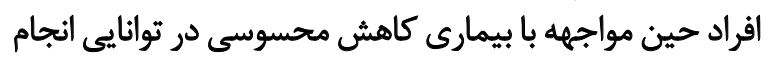

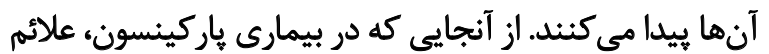

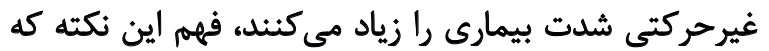

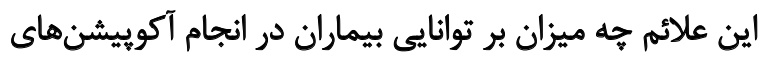

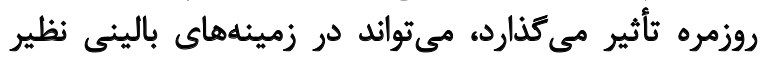

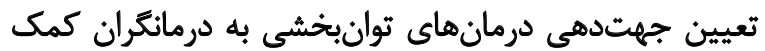

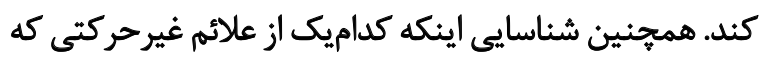

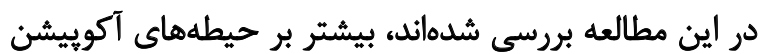

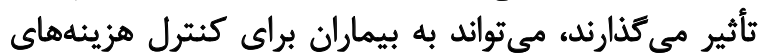

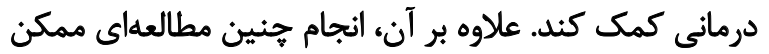

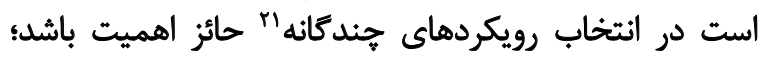

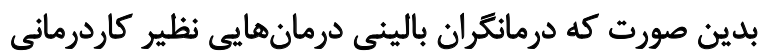

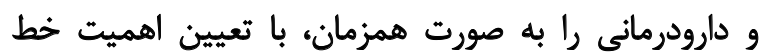

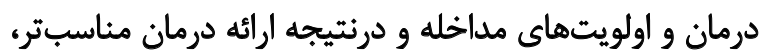

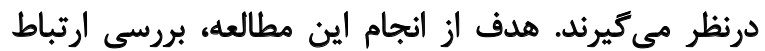

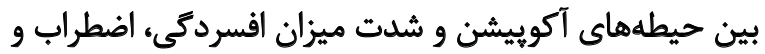
استرس در بيماران هاركينسون بود.

ووشي بروسي اين مطالعه از نوع مقطعى (توصيفىتحليلى) بود. حجم

21. Multidisciplinary 
افسردگى، اضطراب و استرس سنجش و مقايسه شدنده سيس

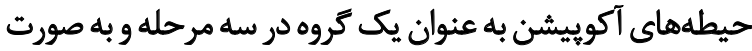

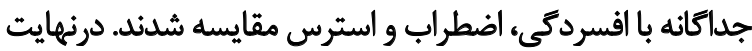

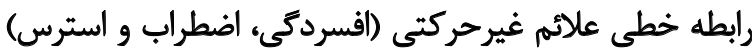

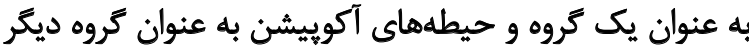

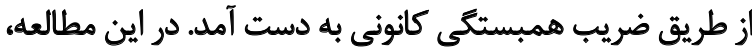

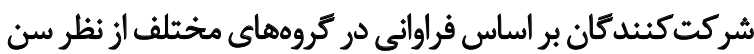

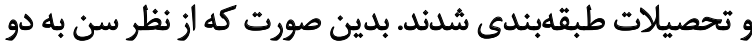

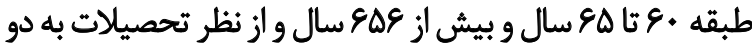

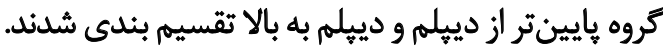

اجراى اين مطالعه حدود 9 ماه طول كشيد. در اين يثروهش، از

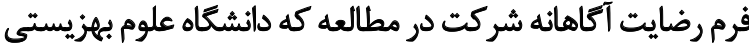

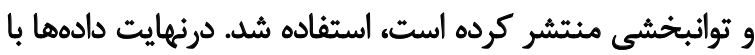

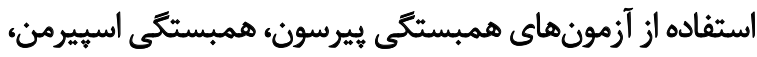

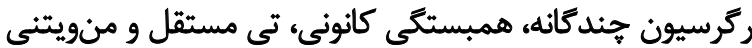

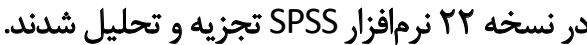

يافتها

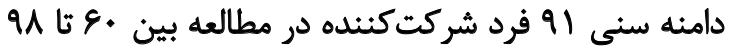

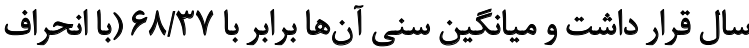

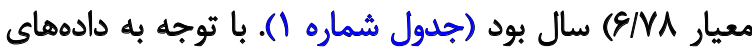

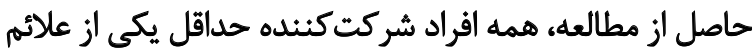

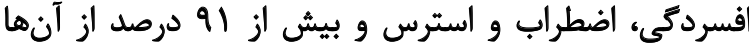

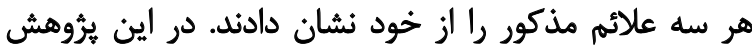

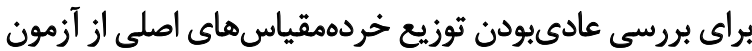

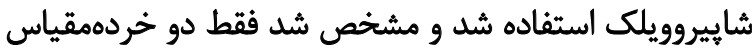

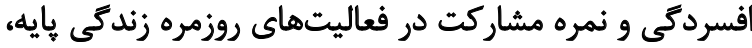

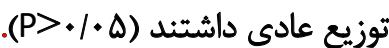

با توجه به نتايج جداول شماره Y و "ا، بين نمره مشاركت در

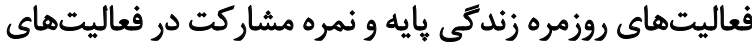

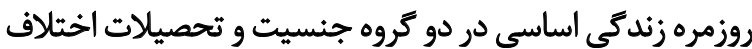

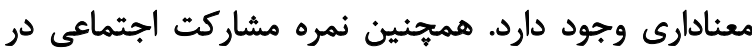

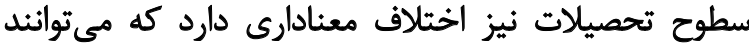

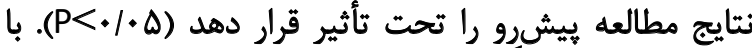

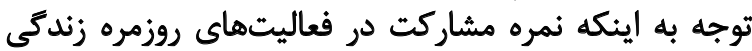

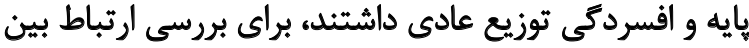

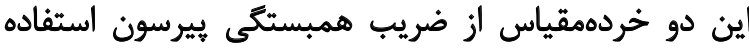

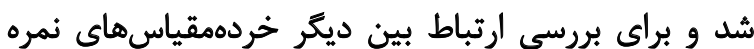

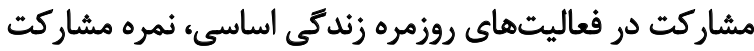

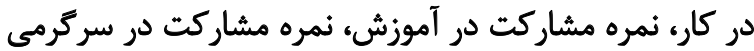

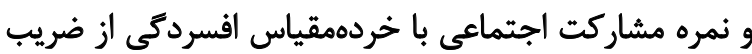
همبستخى اسيبرمن استفاده شد. نتايج نشان داد ميزان همبستگى بين دو خردممقياس نمره
إز شكل كوتاه آزمون استفاده شده است، به منظور طبقهبندى

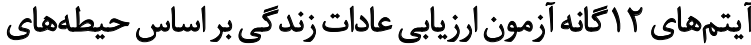

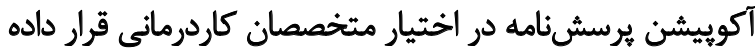

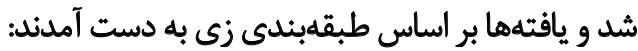

انجام كارهاى منزل، مراقبت شخصى و تغذيه زيرمجموعه

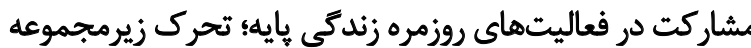

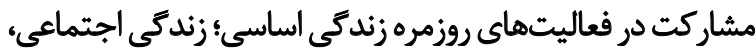

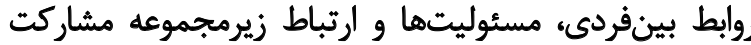

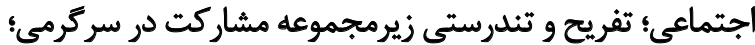

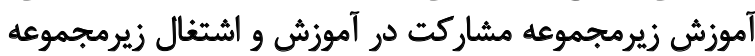

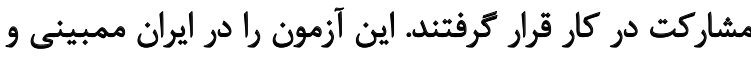
همكارانش در سال ها • r رواو و پايا كردند.

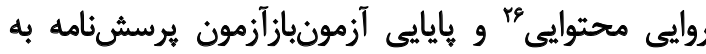

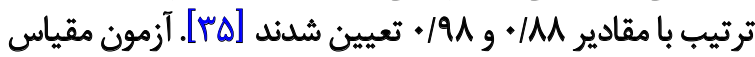

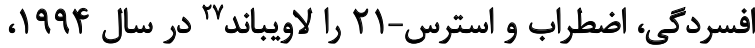

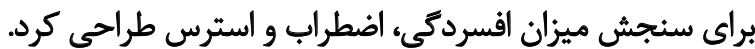

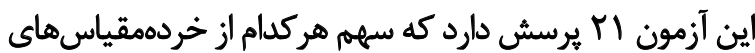

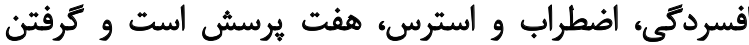

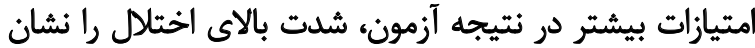

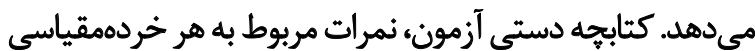

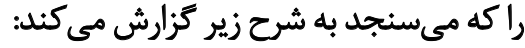

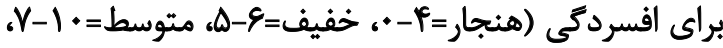

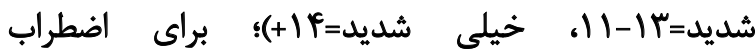

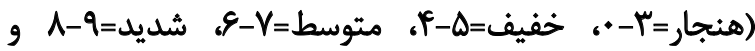

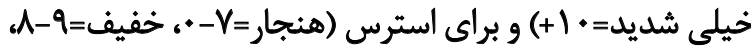

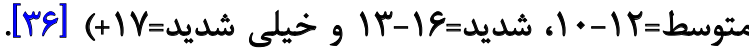

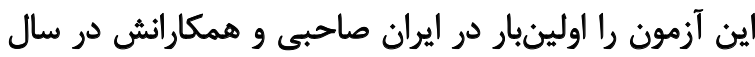

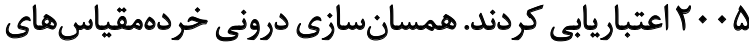

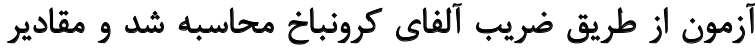

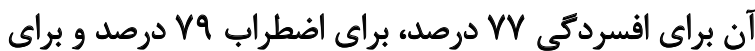

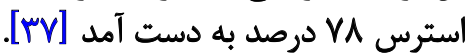

نحوه ياسخدادن شركت كنيدكان بر اساس مدتزمان اجراي

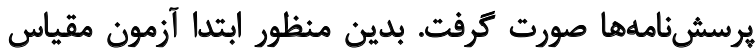

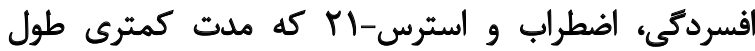

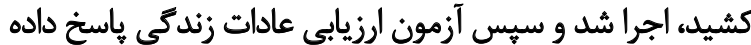

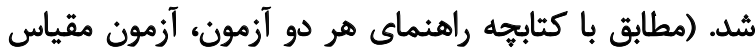

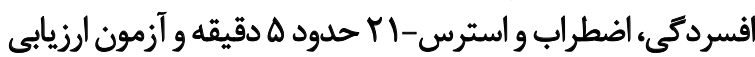

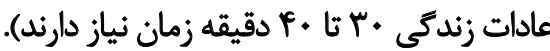
در يروهش حاضر، دادهها در سه مرحله آناليز شدند. ابتدا

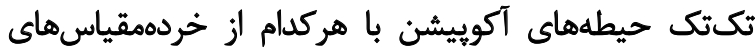

\section{Content Validity Index}

27. Lovibond 
جدول ا. توزيع خردممقياس هاى جمعيتشناختي شركت كنيندان در مطالعه (n=91)

\begin{tabular}{|c|c|c|c|}
\hline درصد & تعداد & زيركروه & خردهمقياس \\
\hline$r \cdot N$ & 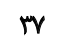 & •و تا هاع سال & \\
\hline$\Delta Q / \mu$ & $\Delta r^{p}$ & ه & سن \\
\hline$E N 1$ & er & مرد & \\
\hline$r v / q$ & rq & & جنسيث \\
\hline aNY & ar & كرييلم & تحصيلات \\
\hline$F / 1 / A$ & MA & دييلم>> & \\
\hline$r E / T V$ & ar & مردان & \\
\hline YE/QA & rq & زنان & - Slinari \\
\hline$r \Delta / N \Delta$ & $\Delta r$ & >دييلم & \\
\hline TVIA & M & دييلم/> & \\
\hline
\end{tabular}

براى بررسى ارتباط بين هر كدام از خردهمقياسهاى نمره

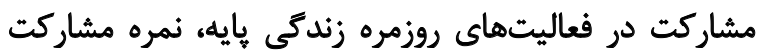

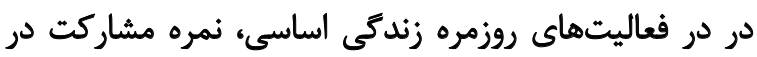

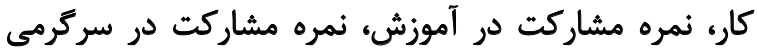

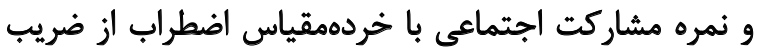
همبستخى اسيّيرمن استفاده شد.

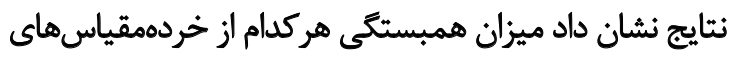

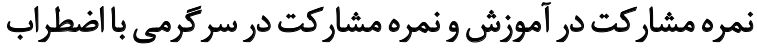

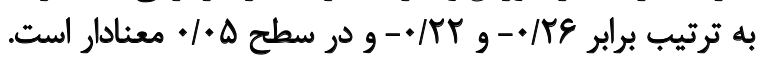

مشاركت در فعاليتهاى روزمره زندكى يايه و افسردگى برابر

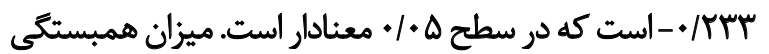

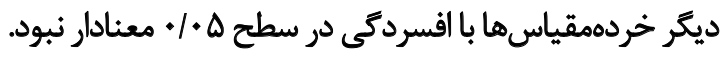

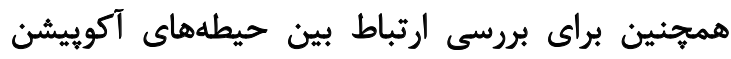

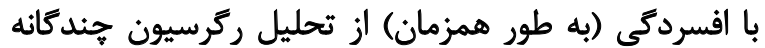

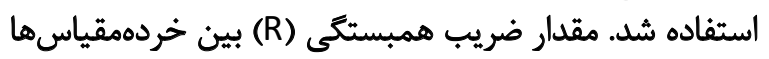

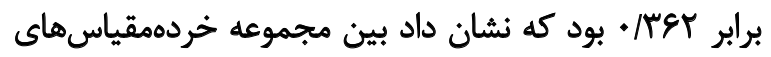

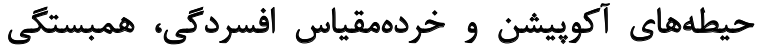

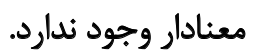

جدول T. نتايج آزمون تى مستقل براى ميزان اختلاف بين خردهمقياسهاى جمعيتشناختى وخردهمقياس هاى اصلى يُؤهش (الف)

\begin{tabular}{|c|c|c|c|c|c|}
\hline مقدار احتمال" & مقدار تى & مياتكين & زيركتروه & & خردهمقياسها \\
\hline.$/ 99$ & $.1 \% 1$ & $\begin{array}{l}\text { YV/OV } \\
\text { TV/OA }\end{array}$ & 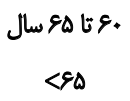 & سن س & \\
\hline.$/ r \gamma$ &.$- / 91$ & $\begin{array}{l}r / 19 \\
r T / m r\end{array}$ & 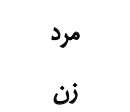 & جنسيت & |فسردكى \\
\hline.$/ 1 F$ & $1 / 19$ & $\begin{array}{l}r T / \pi \\
r \cdot / O T\end{array}$ & دييلم كييلم & تحصيلات & \\
\hline.$/ 4 T$ & - MAr & $\begin{array}{l}\Delta / P V \\
\Delta / I V\end{array}$ & 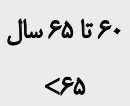 & سن & \\
\hline .101 & $-T / \Delta \Delta$ & $\begin{array}{l}r / Q u \\
\text { s/ar }\end{array}$ & مرد & جنسيت & ثمره مشاركت در فعاليتهاى روزمره \\
\hline $.1 . .1$ & $-r / \Delta$ & $\begin{array}{l}\text { P/N } \\
\text { G/. }\end{array}$ & دييلميلم & تحصيلات & \\
\hline
\end{tabular}


جدول با. نتايج آزمون منويتنى براى ميزان اختلاف بين خردممقياسهاى جمعيتشناختى و خردمقياس هاى اصلى يُروهش (ب)

\begin{tabular}{|c|c|c|c|c|c|}
\hline مقدار احتمال - & zقدار z & مياتكين & زيرتروه & & خردهمقياسها \\
\hline$\cdot M$ &.$- / \pi V$ & $\begin{array}{l}r / / \mu q \\
r / \cdot r\end{array}$ & 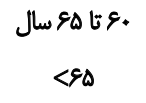 & سن سن & \\
\hline 促 & $-1 / 1 r$ & $\begin{array}{l}r / q T \\
r r / q\end{array}$ & من & جنسيت & اضطراب \\
\hline . AP &.$- / T$ & $\begin{array}{l}r / \pi A \\
r / / \oplus \Delta\end{array}$ & دييلمي كيلم & تحصيلات & \\
\hline ./IV & $-1 / 79$ & $\begin{array}{l}r T / \Delta I \\
r \Delta / P A\end{array}$ & 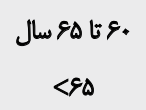 & 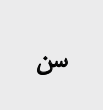 & \\
\hline . /90 & -.1 .8 & $\begin{array}{l}r / M \\
r e / g r\end{array}$ & زن & جنسيت & استرس \\
\hline 年 $1 / 49$ &.$- / 1 \Delta \infty$ & $\begin{array}{l}r \% / M P \\
r A / P\end{array}$ & دييلميلم & تحصيلات & \\
\hline . $/ \Delta P$ &.$- / 8 T$ & $\begin{array}{l}F / M A \\
F / M\end{array}$ & 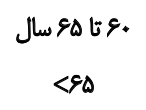 & سن - ل من & \\
\hline$+/+r+\infty$ & $-r / .9$ & $\begin{array}{l}\text { P/ME } \\
\text { D/AV }\end{array}$ & زن & جنسيت & 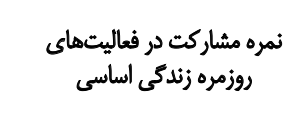 \\
\hline$\%$ & $-r / \% A$ & $\begin{array}{l}F / F Y \\
\Delta / Y Y\end{array}$ & دييله > >ييلم & تحصيلات & \\
\hline . &.$- / 91$ &.$/ W r$ & 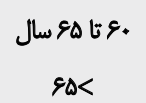 & سن سن & \\
\hline.$/ \Delta V$ & -.109 &.$/ r r$ & مرد & جنسيت & نمره هشاركت در كار \\
\hline 政 & $-1 / r$ & $\begin{array}{l}. / 48 \\
. / 9 q\end{array}$ & $\begin{array}{l}\text { >دييلم } \\
\text { >ييلم }\end{array}$ & تحصيلات & \\
\hline Tा/ &.$- / 44$ & $\begin{array}{l}.114 \\
.194\end{array}$ & 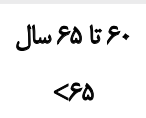 & سن سن & \\
\hline $.1 \Delta \Delta$ &.$- / 8$ & $\begin{array}{l}. / \Delta \Delta \\
. / 1 Y\end{array}$ & زن & جنسيت & نمره مشاركت در آموزش \\
\hline$\% \bullet$ & $-1 / A$ & $\begin{array}{l}. / . r \\
. / 9 r\end{array}$ & بيايينتر & تحصيلات & \\
\hline$. / \Delta \mid$ & -.198 & $\begin{array}{l}\text { T/AY } \\
\text { T/AY }\end{array}$ & 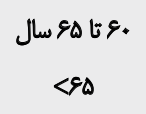 & سن سن & \\
\hline . $/ \Delta V$ &.$- / \Delta V$ & $\begin{array}{l}r / M \\
T / M\end{array}$ & زن & جنسيت & نمره مشاركت در سركرمى \\
\hline.$/ M$ &.$- / \pi$ & $\begin{array}{l}r / 9 \\
r / 1\end{array}$ & دييلميلم & تحصيلات & \\
\hline
\end{tabular}




\begin{tabular}{|c|c|c|c|c|c|}
\hline مقدار احتمال - & مقدار z & مياتكين & زيركروه & & خردهمقي \\
\hline.$/ \Delta V$ &.$- / 10 Y$ & $\begin{array}{l}\Delta / \nabla V \\
\Delta / T \Delta\end{array}$ & 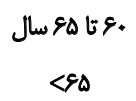 & سن & \\
\hline .188 &.$- / M T$ & $\begin{array}{l}\Delta / F A \\
\Delta / T r\end{array}$ & زن & جنسيت & نمره هشاركت اجتماعى \\
\hline$+1 * \omega^{* *}$ & $-r / A$ & $\begin{array}{l}p / q \\
\text { s/ }\end{array}$ & دييلم > >ييلم & تحصيلات & \\
\hline
\end{tabular}

همجنين همبستكى بين نمره مشاركت در فعاليتهاى روزمره بحث

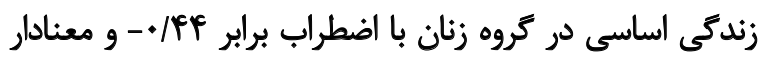

كُروهش حاضر با هدف بروسي ارتباط ميان حيطههاي

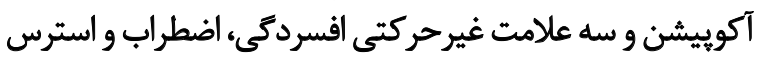

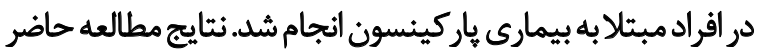

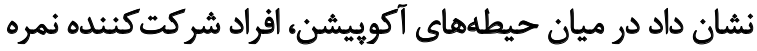

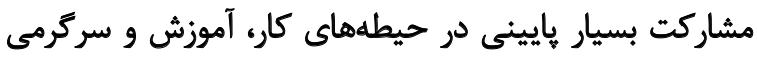

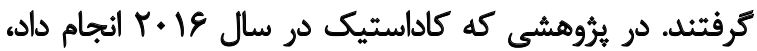

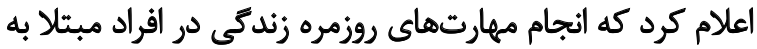

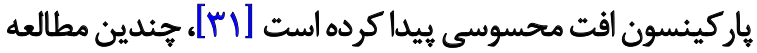

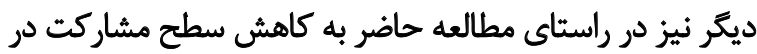

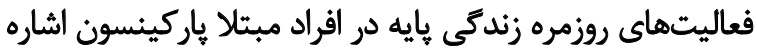

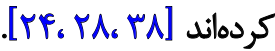

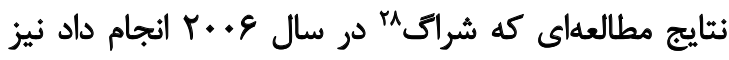
حاكى از آن بود كه عملكرد حركتى ضعيف ناشيى از بيمارى هاركينسون سبب انزواى اجتماعي و در نتيجه كاهش آن سطح

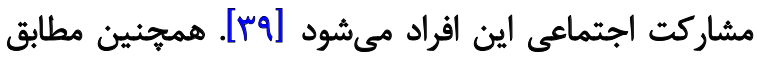

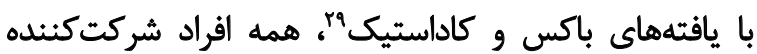
در مطالعه يميشرو حداقل يكي از علائم افسردكي، اضطراب

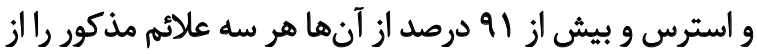

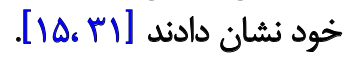

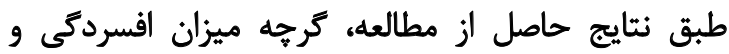
اضطراب در كروه زنان بيشتر از مردان است است، اما اين علائم

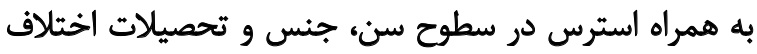

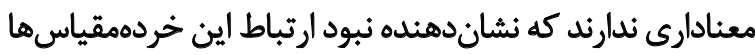
با الفسردكى، اضطراب و استرس است. مطالعه كاداستيك به به اثبات

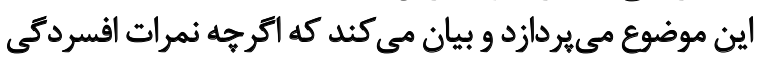

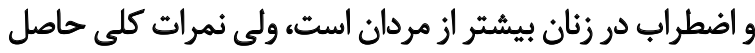

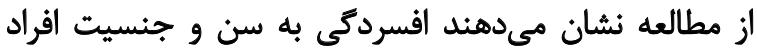

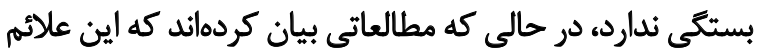

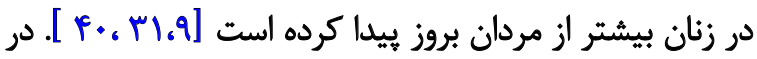

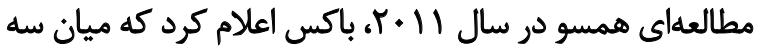

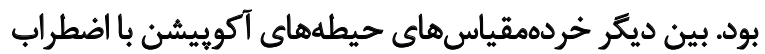

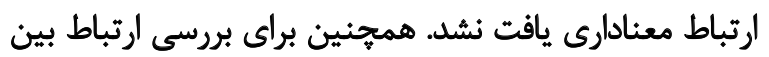

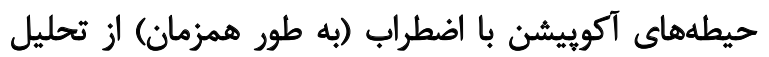

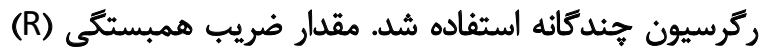

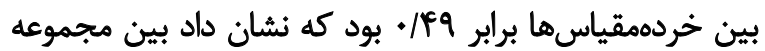

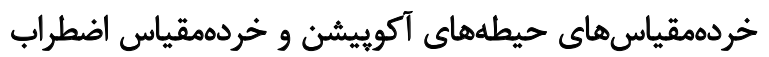
همبستكَي معنادار وجود دارد.

براي بررسي ارتباط بين هركدام از خردهمقياسهاي نمره

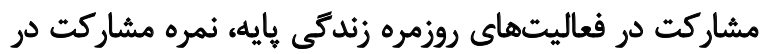

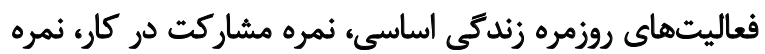

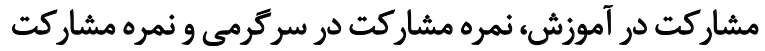

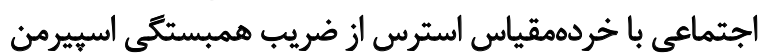
استثاده شد.

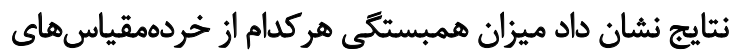

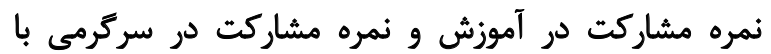

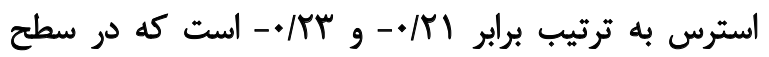

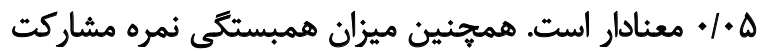

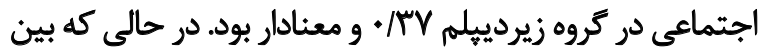

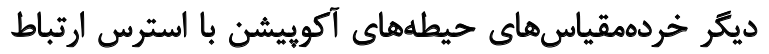
معنادارى يافت نشد.

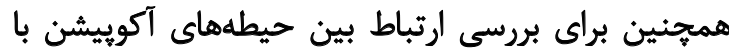

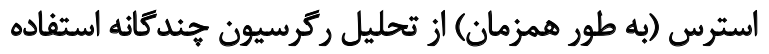

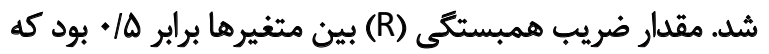

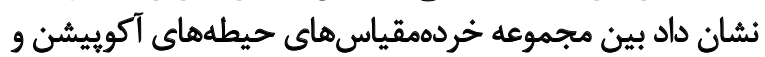
خردهمقياس استرس همبستخى معنادار وجود دارد.

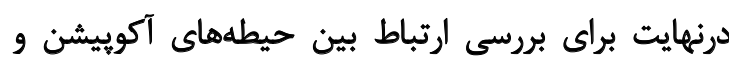

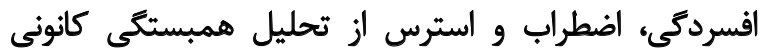

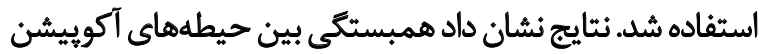

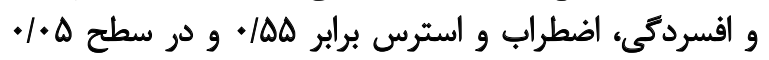
درصد معنادار است. 
كاداستيك اين موضوع را تأييد مي كند كه افسردگى و مشاركت

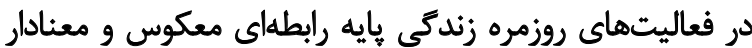

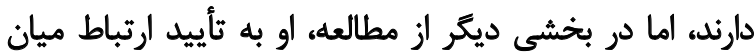

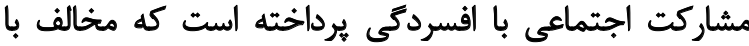
نتيجهى بروهش حاضر است [است]

مطابق با يافته كاداستيك، ياتريك نيز در يُؤهشى در سال

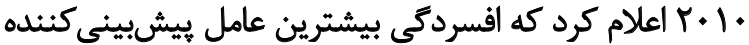

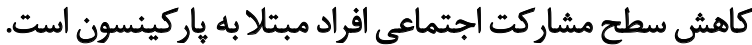

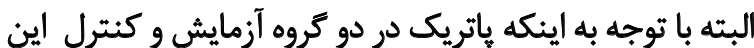

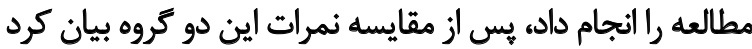

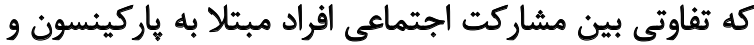

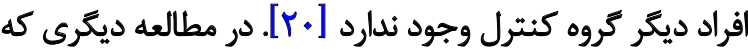

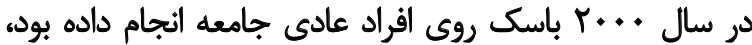

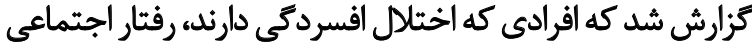

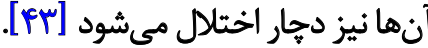

\section{ارثباط ميان حيطه هاي محثتلف أكوييشن و أسترس}

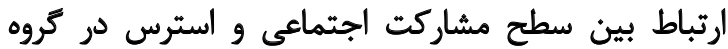

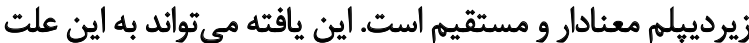

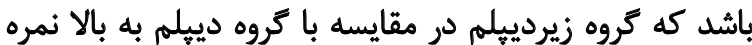

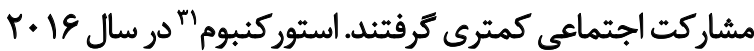

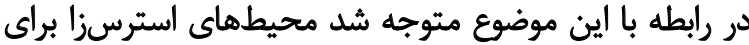

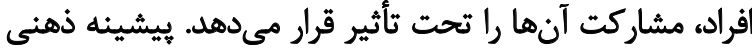

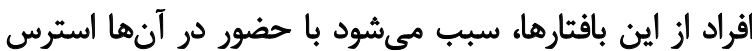

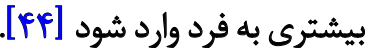

\section{نتيجلهَيرى}

نتايج يثروهش حاضر نشان داد در حالت كلى بين حيطههاى

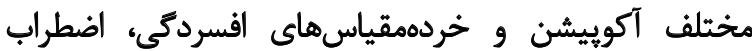

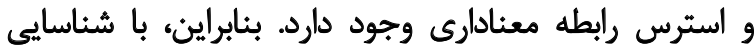

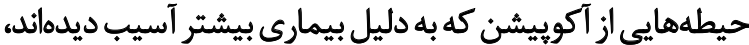

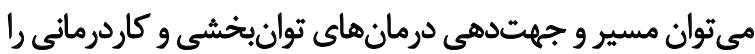

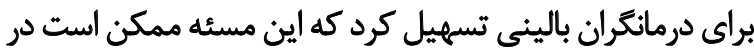

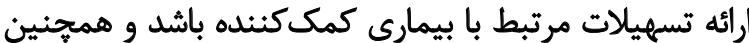

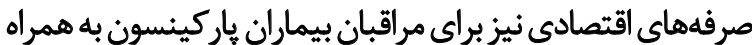

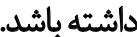

از طرفى، اكر مشاركت بيماران هاركينسون در حيطههاى

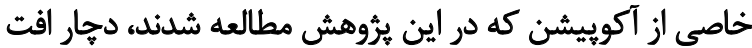

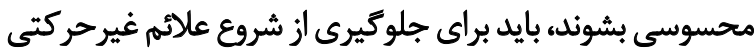

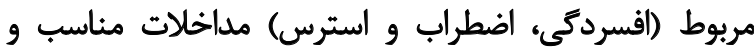
بهموقع صورت كيرد. بنابراين با توجه به نتايج بهدست آمده آناز

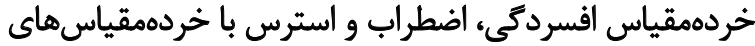

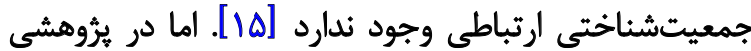

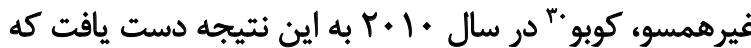

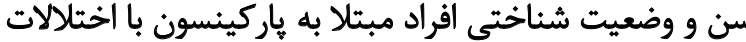

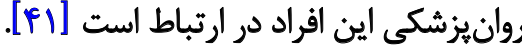
از نظر ارتباط حيطههاي مختلف آكويشيشن باخردهمقياسهاي

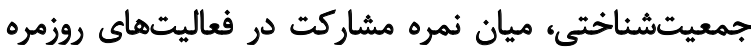

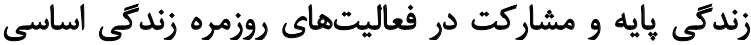

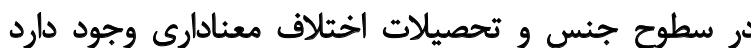

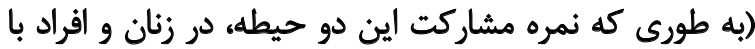

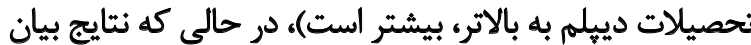

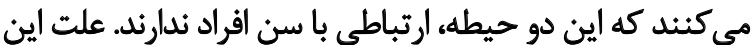

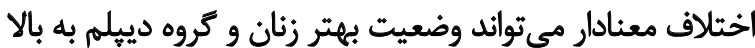

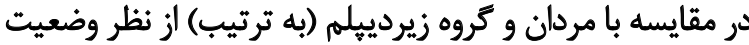
شناختي در مطالعه حاضر باشد.

همجنين تعداد بيشترى از زنان، تحصيلات دييلم به بالا

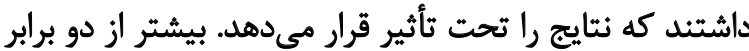

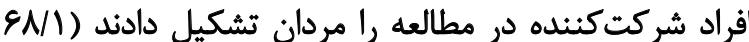

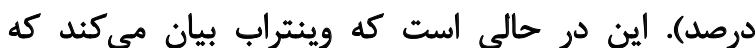
هيجكدام از مشخصههاي جمعيتشناختى و باليت بالينى (به جز

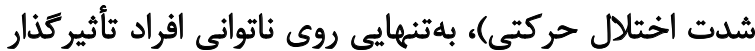

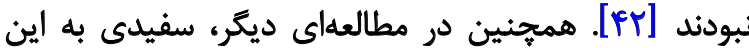

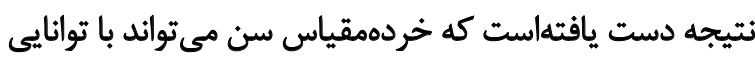

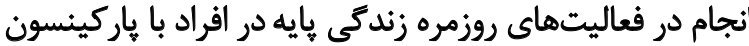

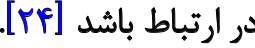

همجنين ميان نمره مشاركت اجتماعى و تحصيلات نيز

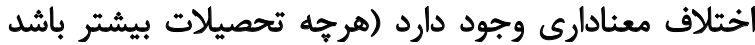

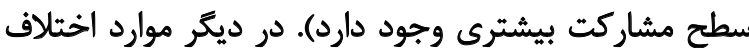

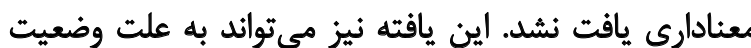

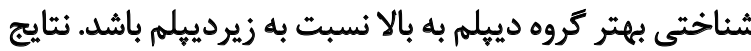

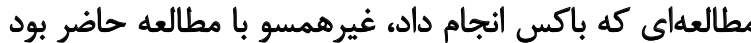

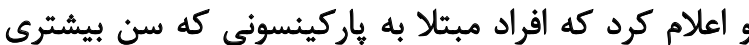

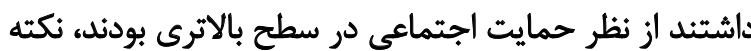

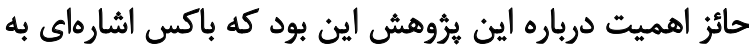

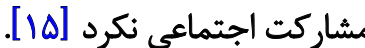
ار تباط ميان حيطهاي مخثلف آكويشيشن و أفسردمّى نتايج مطالعه نشان داد بين دو خردهمقياس نمره مشاركت

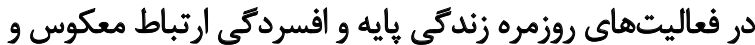

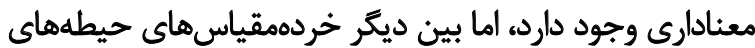

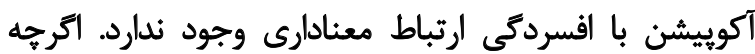

30. Cubo 
مشاركت نويسند مكان

مفهومسازى: اميد فرجيور خزاعى، ابراهيم يُيشياره، مهدى

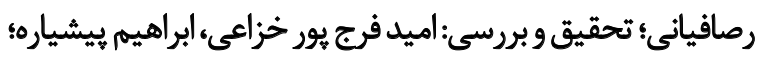

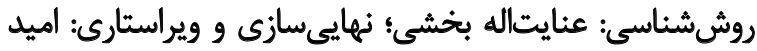

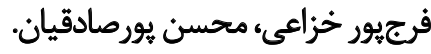

$$
\text { تعارض مناقع }
$$

بنابر اظهار نويسندكان، اين مقاله تعارض منافع ندارد.

$$
\text { تشكر و قدردانى }
$$

در اين بخش بر خود واجب مي دانيم كه مراتب تشكر واني

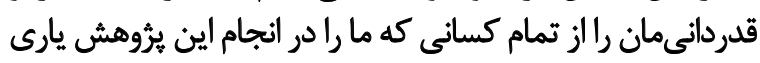

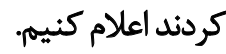

مطالعه حاضر و ارتباط بين برخى حيطهاي آكوييشن با علاثم

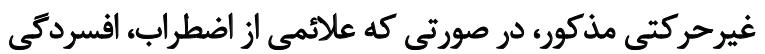

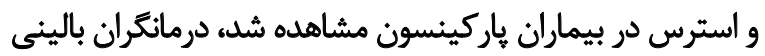

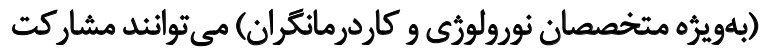

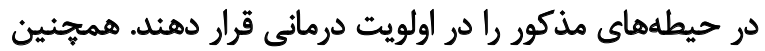

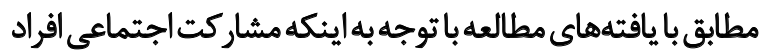

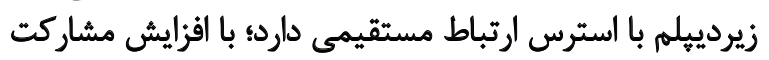

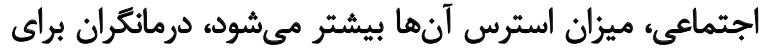
كاهش استرس مي توانثد مداخله هاي لازم را انجام دهنئد مطالعه حاضر فقط وجود ارتباط بين حيطههاى آكويشين و وردي

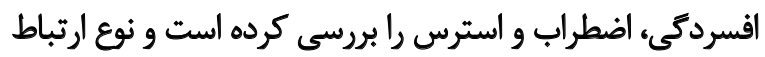

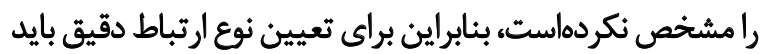

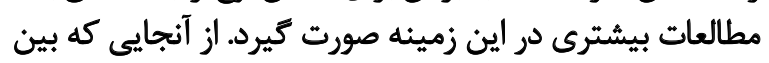

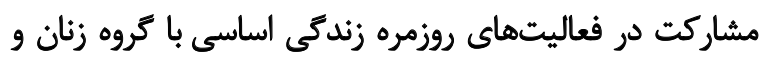

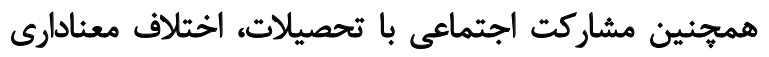

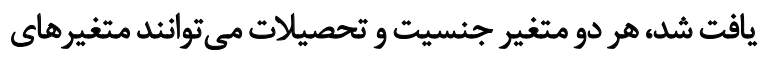

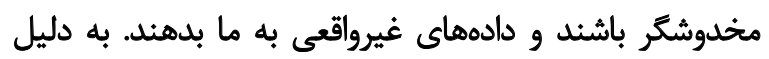

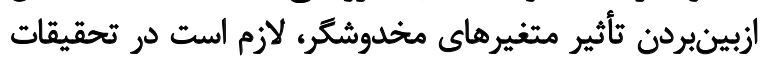
آتى متغيرهاى سن، جنسيت و تحصيلات كنترل شوند.

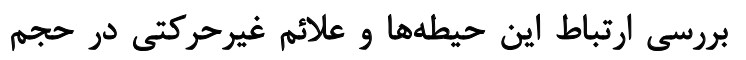

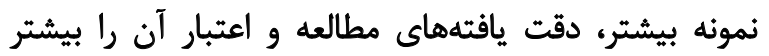

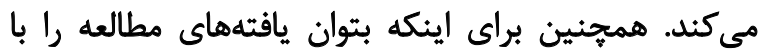

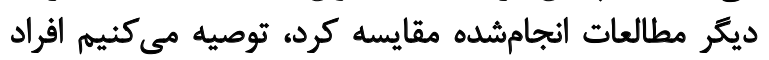

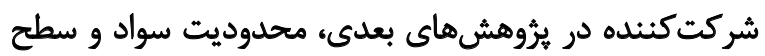
شناختى نداشته باشند.

از آنجايى كه نمونهيرى به صورت دائ دردسترس آسان انجام

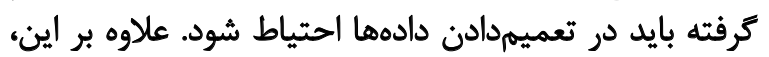

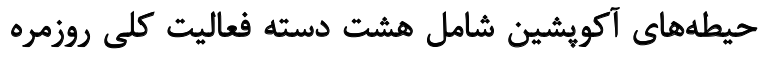

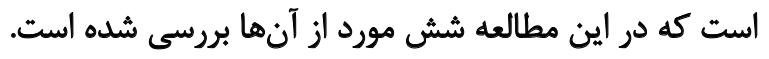

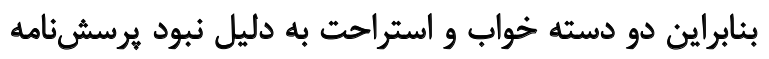

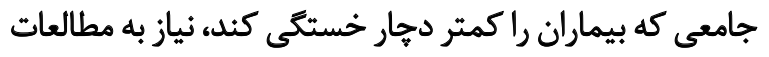
بيشترى دارند.

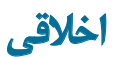
ييروى أز اصول اخلاق يثروهش IR.USWR. اين مطالعه در جلسه شوراي يُروهش باكد اخلاقى REC.1397.018 اين مطاعه دريب شوري شد.

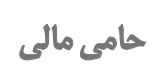

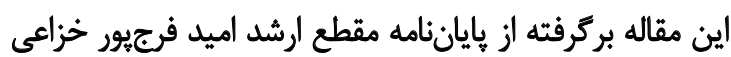

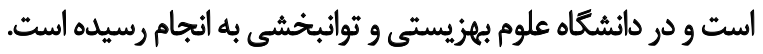




\section{References}

[1] Nilsson FM, Kessing LV, Bolwig TG. Increased risk of developing Parkinson's disease for patients with major affective disorder: A register study. Acta Psychiatrica Scandinavica. 2001; 104(5):380-6. [DOI:10.1111/j.1600-0447.2001.00372.x] [PMID]

[2] Advocat J, Enticott J, Vandenberg B, Hassed C, Hester J, Russell $G$. The effects of a mindfulness-based lifestyle program for adults with Parkinson's disease: A mixed methods, wait list controlled randomised control study. BMC Neurology. 2016; 16(1):166. [DOI:10.1186/s12883-016-0685-1] [PMID] [PMCID]

[3] Majdinasab F, Moradi N, Karkheiran S, Kamali M. [Voice Handicap Index (VHI) in Persian speaking Parkinson's disease patients (Persian)]. Salmand. 2014; 9(1):40-5.

[4] Fereshtehnejad SM, Shafieesabet M, Rahmani A, Delbari A, Lökk J. Medium-to-high prevalence of screening-detected parkinsonism in the urban area of Tehran, Iran: Data from a community-based door-to-door study. Neuropsychiatric Disease and Treatment. 2015; 11:321-32. [DOI:10.2147/NDT.S77391] [PMID] [PMCID]

[5] Chaudhuri KR, Yates L, Martinez-Martin P. The non-motor symptom complex of Parkinson's disease: A comprehensive assessment is essential. Current Neurology and Neuroscience Reports. 2005; 5(4):275-83.[DOI:10.1007/s11910-005-0072-6] [PMID]

[6] Troeung L, Gasson N, Egan SJ. Patterns and predictors of mental health service utilization in people with Parkinson's disease. Journal of Geriatric Psychiatry and Neurology. 2015; 28(1):12-8.[DOI:10.1177/0891988714541869] [PMID]

[7] Chaudhuri KR. Quantitation of non-motor symptoms in parkinsons disease. European Journal of Neurology. 2008; 15(S2):2-8. [DOI:10.1111/j.1468-1331.2008.02212.x] [PMID]

[8] Barone P, Antonini A, Colosimo C, Marconi R, Morgante L, Avarello TP, et al. The PRIAMO study: A multicenter assessment of nonmotor symptoms and their impact on quality of life in Parkinson's disease. Movement Disorders. 2009; 24(11):16419. [DOI:10.1002/mds.22643] [PMID]

[9] Krishnan S, Sarma G, Sarma S, Kishore A. Do nonmotor symptoms in Parkinson's disease differ from normal aging? Movement Disorders. 2011; 26(11):2110-3. [DOI:10.1002/ mds.23826] [PMID]

[10] Kim HS, Cheon SM, Seo JW, Ryu HJ, Park KW, Kim JW. Nonmotor symptoms more closely related to Parkinson's disease: Comparison with normal elderly. Journal of the Neurological Sciences. 2013; 324(1):70-3. [DOI:10.1016/j.jns.2012.10.004] [PMID]

[11] Guo X, Song W, Chen K, Chen X, Zheng Z, Cao B, et al. Gender and onset age-related features of non-motor symptoms of patients with Parkinson's diseasea: A study from Southwest China. Parkinsonism \& Related Disorders. 2013; 19(11):961-5. [DOI:10.1016/j.parkreldis.2013.06.009] [PMID]

[12] Špica V, Pekmezović T, Svetel M, Kostić VS. Prevalence of non-motor symptoms in young-onset versus late-onset Parkinson's disease. Journal of Neurology. 2013; 260(1):131-7. [DOI:10.1007/s00415-012-6600-9] [PMID]
[13] Gallagher DA, Lees AJ, Schrag A. What are the most important nonmotor symptoms in patients with Parkinson's disease and are we missing them? Movement Disorders. 2010; 25(15):2493-500. [DOI:10.1002/mds.23394] [PMID]

[14] Martinez-Martin P, Rodriguez-Blazquez C, Kurtis MM, Chaudhuri $K$. The impact of non-motor symptoms on health-related quality of life of patients with Parkinson's disease. Movement Disorders. 2011; 26(3):399-406. [DOI:10.1002/mds.23462] [PMID]

[15] Bucks RS, Cruise KE, Skinner TC, Loftus AM, Barker RA, Thomas MG. Coping processes and health-related quality of life in Parkinson's disease. International Journal of Geriatric Psychiatry. 2011; 26(3):247-55. [DOI:10.1002/gps.2520] [PMID]

[16] Chaudhuri KR, Healy DG, Schapira AHV. Non-motor symptoms of Parkinson's disease: Diagnosis and management. The Lancet Neurology. 2006; 5(3):235-45. [DOI:10.1016/S14744422(06)70373-8]

[17] Jankovic J. Parkinson's disease: Clinical features and diagnosis. Journal of Neurology, Neurosurgery, and Psychiatry. 2008; 79(4):368-76. [DOI:10.1136/jnnp.2007.131045] [PMID]

[18] Hadinia A, Meyer A, Nowak K, Gschwandtner U, Fuhr P. Cognitive Behavioral Group Therapy (CBT) for stress reduction in patients with Parkinson's disease: A randomized control trial. Parkinsonism \& Related Disorders. 2016; 22:e12-3. [DOI:10.1016/j.parkreldis.2015.10.166]

[19] Poursadeghiyan M, Abbasi M, Mehri A, Hami M, Raei $M$ Ebrahimi MH. [Relationship between job stress and anxiety, depression and job satisfaction in nurses in Iran (Persian)]. The Social Sciences. 2016; 11(9):2349-55.

[20] McNamara P, Stavitsky K, Durso R, Harris E. The impact of clinical and cognitive variables on social functioning in Parkinson's disease: Patient versus examiner estimates. Parkinson's Disease. 2010; 2010(263083):1-6. [DOI:10.4061/2010/263083] [PMID] [PMCID]

[21] Heydaripoor M, Mashhadi A, Nekah A, Mohsen S. [Relationship between personality characteristics, emotional intelligence and quality of life mental health of people with disabilities (Persian)]. Archives of Rehabilitation. 2013; 14(1):40-9.

[22] Chehelamirani N, Sahaf R, Rassafiani M, Bakhshi E. [Validity and reliability of WHOQOL-DIS Questionnaire in Iranian older people with disability (Persian)]. Archives of Rehabilitation. 2016; 16(4):334-45

[23] Barbara A, Glen G, Marjorie E, Cohn ES. Willard_and_spackmans-occupational-therapy. Philadelphia: Wolters Kluwer Health/Lippincott Williams \& Wilkins; 2014.

[24] Heris TS, Akbarfahimi M, Lajevardi L. Safety predictors in performance of activities of daily living in patients with Parkinson's disease. Middle East Journal of Rehabilitation and Health Studies. 2018; 5(1):e14898. [DOI:10.5812/mejrh.14898]

[25] Roger KS, Medved M. Living with Parkinson's disease-managing identity together. International Journal of Qualitative Studies on Health and Well-being. 2010; 5(2):5129. [DOI:10.3402/ qhw.v5i2.5129] [PMID] [PMCID] 
[26] Huber M, Knottnerus JA, Green L, van der Horst H, Jadad AR, Kromhout D, et al How should we define health? BMJ. 2011; 343:d4163. [DOI:10.1136/bmj.d4163] [PMID]

[27] Sturkenboom IH. Occupational therapy for people with Parkinson's disease: Towards evidence-informed care. Berlin: Springer; 2016.

[28] Lawrence BJ, Gasson N, Kane R, Bucks RS, Loftus AM. Activities of daily living, depression, and quality of life in Parkinson's disease. PLOS One. 2014; 9(7):e102294. [DOI:10.1371/journal. pone.0102294] [PMID] [PMCID]

[29] Eser HY, Bora HA, Kuruoglu A. Depression and Parkinson disease: Prevalence, temporal relationship, and determinants. Turkish Journal of Medical Sciences. 2017; 47(2):499-503. [DOI:10.3906/sag-1603-101] [PMID]

[30] Shulman LM, Taback RL, Rabinstein AA, Weiner WJ. Nonrecognition of depression and other non-motor symptoms in Parkinson's disease. Parkinsonism \& Related Disorders. 2002; 8(3):193-7.[DOI:10.1016/S1353-8020(01)00015-3]

[31] Kadastik-Eerme L, Muldmaa M, Lilles S, Rosenthal M, Taba N, Taba P. Nonmotor features in Parkinson's disease: What are the most important associated factors? Parkinson's Disease. 2016; 2016(4370674):1-8. [DOI:10.1155/2016/4370674] [PMID] [PMCID]

[32] Raggi A, Leonardi M, Carella F, Soliveri P, Albanese A, Romito LM. Impact of nonmotor symptoms on disability in patients with Parkinson's disease. International Journal of Rehabilitation Research. 2011; 34(4):316-20. [DOI:10.1097/ MRR.0b013e32834d4b66] [PMID]

[33] Seyedian Mf, M. [Validity and reliability of MMSE. Journal of Medical Council of Iran (Persian)]. 2007; 25(4):408-14.

[34] Fougeyrollas P, Noreau L, Bergeron H, Cloutier R, Dion S, StMichel G. Social consequences of long term impairments and disabilities: Conceptual approach and assessment of handicap. International Journal of Rehabilitation Research. 1998; 21(2):127-41. [DOI:10.1097/00004356-199806000-00002] [PMID]

[35] Noori-Mombeyni N, Mosallanezhad Z, Rassafiani M, Afshar S, Bakhshi E, Sotoudeh GhR, et al. [Validity and reliability of the Persian version of the life habits assessment questionnaire for older adults (Persian)]. Journal of Research in Rehabilitation Sciences. 2015; 11(1):11-6.

[36] Henry JD, Crawford JR. The short-form version of the Depression Anxiety Stress Scales (DASS-21): Construct validity and normative data in a large non-clinical sample. British Journal of Clinical Psychology. 2005; 44(2):227-39. [DOI:10.1348/014466505X29657] [PMID]

[37] Sahebi A, Asghari MJ, Salari RS. Validation of Depression Anxiety and Stress Scale (DASS-21) for an Iranian population. Iranian Psychologists. 2005; 4(1):299-313.

[38] sWang S, Mao S, Xiang D, Fang C. Association between depression and the subsequent risk of Parkinson's disease: A meta-analysis. Progress in Neuro-Psychopharmacology and Biological Psychiatry. 2018; 86:186-92. [DOI:10.1016/j.pnpbp.2018.05.025] [PMID]
[39] Cusso M, Sewram A, Pountney D, Donald K, Khoo T. The association of perceived stress and the frequency and severity of non-motor symptoms in Parkinson's disease. Parkinsonism \& Related Disorders. 2018; 46(Suppl. 2):e12. [DOI:10.1016/j. parkreldis.2017.11.040]

[40] Tan YY, Yen LT, Prerna A. Hidden face of Parkinson's disease: The complexity of non-motor symptoms. Journal of the Neurological Sciences. 2017; 381:1034-5. [DOI:10.1016/j. jns.2017.08.2920]

[41] Salari M, Chitsaz A, Etemadifar M, Najafi MR, Mirmosayyeb $\mathrm{O}$, Bemanalizadeh $\mathrm{M}$, et al. Evaluation of non-motor symptoms and their impact on quality of life in patients with Parkinson's disease, Isfahan, Iran. Iranian Journal of Neurology. 2017; 16(3):118-24. [PMID] [PMCID]

[42] Bugalho P, Lampreia T, Miguel R, Mendonça MD, Caetano A, Barbosa R. Non-motor symptoms in Portuguese Parkinson's disease patients: Correlation and impact on quality of life and activities of daily living. Scientific Reports. 2016; 6:32267. [DOI:10.1038/srep32267] [PMID] [PMCID]

[43] Song W, Guo X, Chen K, Chen X, Cao B, Wei Q, et al. The impact of non-motor symptoms on the health-related quality of life of parkinson's disease patients from Southwest China. Parkinsonism \& Related Disorders. 2014; 20(2):149-52. [DOI:10.1016/j.parkreldis.2013.10.005] [PMID]

[44] Wichowicz HM, Sławek J, Derejko M, Cubała WJ. Factors associated with depression in Parkinson's disease: A cross-sectional study in a Polish population. European Psychiatry. 2006; 21(8):516-20. [DOI:10.1016/j.eurpsy.2006.01.012] [PMID] 